\title{
Fatty acid composition, TLC screening, ATR-FTIR analysis, anti-cholinesterase activity, and in vitro cytotoxicity to A549 tumor cell line of extracts of 3 macroalgae collected in Madeira
}

\author{
N. Nunes ${ }^{1,2}$ - G. P. Rosa ${ }^{3} \cdot$ S. Ferraz ${ }^{1} \cdot$ Maria Carmo Barreto $^{3} \cdot$ M. A. A. Pinheiro de Carvalho ${ }^{1}$
}

Received: 22 April 2019 /Revised and accepted: 26 July 2019 /Published online: 6 August 2019

(C) Springer Nature B.V. 2019

\begin{abstract}
Three macroalgae collected at Madeira Island were included in this study to determine their potential for drug, nutraceutical, food, or supplement application. Fatty acid content was higher in Zonaria tournefortii $\left(12.32 \mathrm{mg} \mathrm{g}^{-1} \mathrm{dw}\right)$ with $16.58 \%$ of PUFAs,

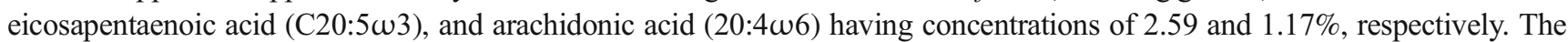
anti-thrombogenic and anti-atherogenicity potential was higher for $Z$. tournefortii due to relevant fatty acids in the biochemical composition this macroalgae. Lipid classes were assessed in the lipid extract and neutral lipids (NL) were in higher yield in Asparagopsis taxiformis (51.16\%) and lower in Z. tournefortii (26.96\%). The glycolipids (GL) were between 36.03 and $16.11 \%$ in Z. tournefortii and Ulva lactuca. Phospholipids (PL) fraction varied from 35.91 and $31.60 \%$ in A. taxiformis and $Z$. tournefortii. TLC screening identified that $U$. lactuca contains phytol and cholesterol in its NL, digalactosyldiacylglycerol in its GL, and cardiolipin and L- $\alpha$-phosphatidylcholine in its PL. Zonaria tournefortii contains phytol and cholesterol in its NL classes, and the PL classes contain L- $\alpha$-phosphatidylethanolamine and 1-(3-sn-phosphatidyl)-rac-glycerol. The macroalgae A. taxiformis revealed cholesterol in its NL fraction and the same phospholipids as $Z$. tournefortii in its PL fraction. ATRFTIR analysis enabled a "fingerprint" spectra and important sulfation absorption bands were identified, revealing the functional polysaccharides within these macroalgae. Anti-cholinesterasic activity was assessed in A. taxiformis, with a low $\mathrm{IC}_{50}$ for $\mathrm{AChE}$ $\left(8.92 \pm 0.43 \mu \mathrm{g} \mathrm{mL} L^{-1}\right)$ and $\mathrm{BuChE}\left(13.96 \pm 0.32 \mu \mathrm{g} \mathrm{mL}^{-1}\right)$, demonstrating dual inhibitory activity, justifying the interest to identify the active principle which may be the scaffold of a novel drug.
\end{abstract}

Keywords Seaweeds $\cdot$ Asparagopsis taxiformis $\cdot$ Ulva lactuca $\cdot$ Zonaria tournefortii $\cdot$ Lipids $\cdot$ PUFAs $\cdot$ MUFAs $\cdot$ SFAs

\section{Introduction}

Nowadays, intensive research is conducted worldwide to explore and determine the nutritive, nutraceutical, pharmaceutical, and cosmeceutical potential of innumerous extracts from organic materials. Seaweeds have been included in this effort

N. Nunes

nuno.nunes@staff.uma.pt

ISOPlexis, University of Madeira Campus da Penteada, 9050-290 Funchal, Madeira, Portugal

2 UBQ II, Unidade de Bioquímica, Lda. Rua Visconde de Anadia, Edifício Anadia $5^{\circ}$ Andar CC, 9050-020 Funchal, Madeira, Portugal

3 cE3c-Centre for Ecology, Evolution and Environmental Changes/ Azorean Biodiversity Group and Faculty of Sciences and Technology, University of Azores, 9501-801 Ponta Delgada, Portugal due to their intrinsic biochemical composition, derived from evolutionary adaptation to the harsh conditions of high salt concentration, desiccation and herbivory, and extreme variations in sunlight and temperature fluctuation. The sea currents and wave energy also cause motional pressure to these organisms, since they must remain attached to the substrate, subjected to additional environmental stress, adjusting the metabolic network and developing new metabolites to permit adaptation to this variable habitat (Mišurcová et al. 2011).

Seaweeds have a low lipid content but are considered a potential source of functional lipids due to their enormous stock in coastal waters. Among total lipids (TL), lipid composition and quantity varies according to species, geographical origin, and environmental conditions (Miyashita et al. 2013). TL are further divided in lipid classes such as glycolipids (GL), triacylglycerols (TAG), and phospholipids (PL). In these classes, fatty acids exist as saturated fatty acids (SFAs), monounsaturated fatty acids (MUFAs), and polyunsaturated fatty acids 
(PUFAs). These last (PUFAs) are essential to human nutrition, since algae produce PUFAs by de novo synthesis and which cannot be biosynthesized by almost all heterotrophic organisms, having to be ingested in the diet. Nowadays, seaweeds are also considered as functional food and nutraceuticals with health benefits, since they are able to reduce the risk of cardiovascular diseases (CVD), diabetes, osteoporosis, and cancer (Mišurcová et al. 2011). GL is the most common lipid group and includes monogalactosyl-diacylglycerols (MGDG), digalactosyl-diacylglycerol (DGDG), and sulfoquinovosyldiacylglycerol (SQDG) (Holdt and Kraan 2011). GLs are important in photosynthetic membranes of higher plants, in algae and bacteria. In brown seaweeds, GLs are the primary membrane lipids, with high concentration of specific long chain fatty acids, which include stearidonic acid (18:4n-3) (SDA), eicosapentaenoic acid (20:5n-3) (EPA), and arachidonic acid (20:4n-6) (ARA) (Miyashita et al. 2013). SDA is formed by the desaturation of $\alpha$-linolenic acid (ALA), and when consumed increases the level of eicosapentaenoic acid (EPA) in erythrocyte membranes (Lemke et al. 2013). Epidemiological experiments demonstrated that ingesting long chain $\omega 3$ fatty acids decreases cardiovascular diseases, mainly heart attacks (Albert et al. 1998). The $\omega 6$ fatty acids are particularly important in biological systems. ARA participates in the immune response, prevents thrombosis, helps brain function, and together with docosahexaenoic acid (DHA), is correlated with a reduction in age-related disorders of the brain and cognitive functions (Hoffman et al. 2009; Kiso 2011). These are the main components of cell membranes and participate in neuron structure in the central nervous system (Miyashita et al. 2013).

Macroalgae are also an interesting source of novel molecules which may be the scaffolds of more efficient drugs, namely against age-related diseases (Barbosa et al. 2014). Alzheimer's disease (AD) is a progressive neurodegenerative disorder, affecting roughly $2 \%$ of the population in industrialized countries, which is characterized by synapse degeneration and neuronal death in regions of the brain responsible for learning and memory processes (Mattson 2004). Two main strategies exist to improve the cholinergic function in $\mathrm{AD}$, which are stimulating cholinergic receptors or increasing the availability of acetylcholine into the neuronal synaptic cleft, inhibiting the enzyme acetylcholinesterase (AChE, E.C. 3.1.1.7) (Howes et al. 2003). Several pharmaceuticals are available for this second strategy and include tacrine, rivastigmine, galantamine, and donepezil; however, the use of these drugs only slows the progress of the illness and causes negative side effects, highlighting the need for new sources of anti-acetylcholinesterasic compounds (Arruda et al. 2012). The inhibition of butyrylcholinesterase or pseudocholinesterase (BuChE, EC 3.1.1.8) may also contribute to the treatment of $\mathrm{AD}$. BuChE is produced mainly in the liver and catalyzes butyrylcholine more rapidly, although it is also able to hydrolyze acetylcholine (Colovic et al. 2013).
Seaweed extracts and pure compounds have been researched for their cytotoxic effect in human A549 lung cancer cellular lines, due to their unique chemical structures that could be used as novel drugs (Alwarsamy et al. 2016). Lung cancer is the most prominent cause of cancer deaths, accounting more than one million deaths worldwide per annum (Lee et al. 2011). This cancer development is characterized by proliferation of anaplastic cells without restraint, invading and metastasizing to the surrounding tissues and organs (Marudhupandi et al. 2015). Several factors are responsible for this illness and include unhealthy diet, inherited genetic mutations, drug use, hormones, environmental toxins, infectious organisms, and immune conditions, the treatment being the obliteration of the tumor cells (Gutiérrez-Rodríguez et al. 2018). Standardized treatment of this malignancy is the application of synthetic compounds in chemotherapy, which attacks the cancer cells but at the same time is cytotoxic to normal cells (Alwarsamy et al. 2016). It is therefore of the utmost importance to discover new sources of bioactive compounds that can reduce this malignancy without the side effects.

This work intended to determine the potential of these 3 seaweeds, due to their significant abundance in Madeira Island. This is an effort to search new sources of bioactive compounds that would help develop purification strategies to research for new pharmaceutical compounds, namely displaying anti-cholinesterasic and/or cytotoxic activity against A549 tumor cell lines. This study will also determine if these macroalgae are good sources of essential fatty acids. These assessments could permit to develop new drugs, new nutraceuticals or to envision new food sources with multiple health applications.

\section{Materials and methods}

\section{Collection of samples}

The chlorophyte macroalga Ulva lactuca Linnaeus was collected on 15 of May 2017, in "Santa Cruz" at coordinates $32^{\circ}$ $41^{\prime} 27^{\prime \prime} \mathrm{N}$ and $16^{\circ} 46^{\prime} 25^{\prime \prime} \mathrm{W}$. The rhodophyte Asparagopsis taxiformis (Delile) Trevisan was collected on 8 of September 2017 and the phaeophyte Zonaria tournefortii (J.V. Lamouroux) Montagne collected on 7 of July 2017 in "Reis Magos" beach, coordinates $32^{\circ} 38^{\prime} 48^{\prime \prime} \mathrm{N}$ and $16^{\circ} 49^{\prime} 26^{\prime \prime} \mathrm{W}$ in a $10 \mathrm{~m}$ maximum depth dive of the Madeiran archipelago. Samples were transported in seawater and gently rinsed with filtered fresh water. Afterwards, a primary drying was applied in which seaweed was frozen at $-35^{\circ} \mathrm{C}$ and freeze-dried for 5 days under reduced pressure $\left(4 \times 10^{-4} \mathrm{mbar}\right)$, with a cooling trap set at $-56{ }^{\circ} \mathrm{C}$. Samples were milled to 200 mesh particle size, vacuum packed, and stored at $-35^{\circ} \mathrm{C}$ until use. 


\section{Fatty acid determination}

The fatty acid (FA) composition was determined according to Lepage and Roy (1986) with the modifications suggested by Cohen et al. (1988) and assessed as FA methyl esters (FAME). Initially, for the conversion of FAs to FAMEs, a mixture of ethyl acetate-methanol $(1: 19 \mathrm{v} / \mathrm{v})$ was added to the dried samples. These were incubated at $80^{\circ} \mathrm{C}$ for $1 \mathrm{~h}$ and followed by an extraction using heptane. The analytical apparatus consisted of a gas chromatograph (Agilent HP 6890), fitted with a mass selective detector (Agilent 5973) and a capillary column DB$225 \mathrm{~J} \& \mathrm{~W}(30 \mathrm{~m} \times 0.25 \mathrm{~mm}$ inner diameter, $0.15-\mu \mathrm{m}$ film thickness), also from Agilent. Chromatographic settings were: helium was used as the carrier gas set to a flow rate of $2.6 \mathrm{~mL} \mathrm{~min}{ }^{-1}$, initial temperature of the oven was set to $35^{\circ} \mathrm{C}$ for a period of $0.5 \mathrm{~min}$, subsequently incremented by $25^{\circ} \mathrm{C} \mathrm{min}{ }^{-1}$ to $195^{\circ} \mathrm{C}$, followed by $3{ }^{\circ} \mathrm{C} \mathrm{min}^{-1}$ to $205^{\circ} \mathrm{C}$ and $8^{\circ} \mathrm{C} \mathrm{min}^{-1}$ to achieve a maximum temperature of $230^{\circ} \mathrm{C}$ for a period of $3 \mathrm{~min}$. Injector temperature was set to $250^{\circ} \mathrm{C}$ and the transfer line set to $280^{\circ} \mathrm{C}$ with the split ratio at 1:100. FAMEs were identified, comparing the retention times and mass spectra fragmentation to standards (bacterial acid methyl esters CP mix and Supelco 37 component FAME mix). The internal standard was heneicosanoic acid (C21:0). Two measures of each sample were performed, presented as mean values \pm standard deviation (SD) of FAME and results expressed in $\mathrm{mg} \mathrm{g}^{-1}$ of dry weight (DW).

The index of thrombogenicity (IT) and the index of atherogenicity (IA), in which lower results indicate a lower risk to develop those pathologies, was calculated as proposed by Ulbricht and Southgate (1991) using the following equations:

$$
\begin{aligned}
& \mathrm{IT}=(14: 0+16: 0+18: 0) / \\
& [(0.5 \times \Sigma \text { MUFA }+0.5 \times \text { PUFA } \omega 6+3 \times \text { PUFA } \omega 3)+(\text { PUFA } \omega 3 / \text { PUFA } \omega 6))] \\
& \mathrm{IA}=[(12: 0+(4 \times 14: 0)+16: 0)] / \\
& \quad[\Sigma \text { MUFA }+ \text { PUFA } \omega 6+\text { PUFA } \omega 3]
\end{aligned}
$$

\section{Extraction and fractionation}

\section{Lipid extraction}

The methodology of Folch et al. (1957), with some modifications, was used to perform the lipid extractions (LE) from the macroalgae. Initially, $2 \mathrm{~g}$ of freeze-dried milled macroalgae were mixed with $40 \mathrm{~mL}$ of $\mathrm{CHCl}_{3}: \mathrm{MeOH}(2: 1)$. Subsequently, it was sonicated for $10 \mathrm{~min}$ at $37 \mathrm{kHz}$ at $100 \%$ and centrifuged at $7197 \mathrm{xg}$ at room temperature. The liquid extract was filtered with a $8-\mu \mathrm{m}$ pore filter paper, added to $8 \mathrm{~mL}$ of $0.9 \% \mathrm{NaCl}$ solution, vortexed, and centrifuged at 470xg for phase separation. The upper phase was removed and discarded, leaving the lipophilic phase. The majority of the solvent was evaporated in a rotary evaporator and the residual solvent evaporated in an oven at $35{ }^{\circ} \mathrm{C}$ overnight and weighed. These extracts will from now on be abbreviated as LE.

\section{Ethanol extraction}

The ethanol extracts (EE) were performed with $96 \%$ ethanol, using a Timatic semiautomatic extractor (Technolab, Spello, Italy), set at a constant pressure and static phase. The program was set as follows: solvent capacity $1 \mathrm{~L}$, solvent to biomass ratio 50:1, compression time $3 \mathrm{~min}$, decompression time 6 min, minimum pressure 6 bar, compression pressure $8.5 \mathrm{bar}$ at room temperature $\left( \pm 23^{\circ} \mathrm{C}\right)$. The number of cycles was set to 12 cycles, which corresponded to $108 \mathrm{~min}$ for each extraction. Each sample of $20 \mathrm{~g}$ was placed in a $100-\mu \mathrm{m}$ mesh bag and placed inside a $0.5-\mathrm{L}$ extracting vessel. In the end of each extraction, the liquid extracts were filtered through a $8-\mu \mathrm{m}$ Whatman filter and were partly evaporated in a rotary evaporator and dehydrated completely in an oven, at $35{ }^{\circ} \mathrm{C}$ until complete dryness. After, these were stored under vacuum at $-35{ }^{\circ} \mathrm{C}$ until use.

\section{Lipid classes}

LE were fractioned into neutral (N), glycolipid (GL), and phospholipid (PL) classes. Initially, $50 \mathrm{mg}$ of extract were solubilized in $2 \mathrm{~mL}$ of chloroform and applied to a glass column with $10 \mathrm{~g}$ of 200 to 400 mesh silica particles. Silica was previously packed with chloroform, with quartz sand beneath and underneath for protection. Fractionation was performed using $100 \mathrm{~mL}$ of a specific solvent for each class. Neutral lipids and sterols were extracted with chloroform, glycolipids with acetone, and phospholipids with methanol. For each extraction, the corresponding solvent containing the lipid class was collected and dried, initially in a rotary evaporator, afterwards in an oven at $35{ }^{\circ} \mathrm{C}$. The residue was weighted and stored at $-35^{\circ} \mathrm{C}$ until use.

\section{Thin layer chromatography}

The separated lipid classes were assessed using thin layer chromatography (TLC) with Macherey-Nagel Pre-coated TLC sheets POLYGRAM SIL G/UV $\mathrm{UV}_{254}(0.20 \mathrm{~mm}$ silica gel $60)$. The TLC mobile phase for neutral lipids was hexane:diethyl ether:acetic acid (85:15:0.1, v/v), and TLC plate was revealed with vanillin solubilized in sulfuric acid $(1: 100, w / v)$, with posterior heating at $120^{\circ} \mathrm{C}$ in an oven until complete dryness of the TLC plate. The standards were cholesterol acetate, cholesterol, $\beta$-carotene, and phytol. The mobile phase for glycolipids was dichloromethane:methanol 
$(85: 15, \mathrm{v} / \mathrm{v})$ and the TLC plate was revealed with $\alpha$ naphthol:sulfuric acid:water:ethanol (2.4:10:10:80, w/v), and the TLC plate heated at $120^{\circ} \mathrm{C}$ for 3 to 5 min, until pink and purple spots were detected. The standard used was digalactosyldiacylglycerol (DGDG). Phospholipids were separated by polarity and charge. The mobile phase was chloroform:methanol:ammonium hydroxide $(65: 25: 4, \mathrm{v} / \mathrm{v})$, revealed with sprayed $10 \%$ copper and $8 \%$ phosphoric acid solubilized in water, and placed in an oven at $120{ }^{\circ} \mathrm{C}$ until spots appeared. The standards used were L- $\alpha$-phosphatidylcholine, L- $\alpha$-phosphatidylethanolamine, 1-(3-sn-phosphatidyl)-rac-glycerol sodium salt, 1,2-diacyl-sn-glycerolphospho-L-serine, cardiolipin sodium salt, and lysophosphatidylcholine. The retention factor (Eq. 1) was calculated in millimeters for the separated compounds within each lipid class, as this is calculated by dividing the distance traveled by the compound and the distance traveled by the solvent front.

\section{Bioactivities}

\section{Anti-cholinesterase activity}

The assays to assess anti-acetylcholinesterase (AChE) and anti-butyrylcholinesterase activities (BuChE) were adapted from Ellman et al. (1961) modified by Arruda et al. (2012). In each microplate, serial dilutions of the extracts were prepared in $100 \mathrm{mM}$ phosphate buffer $\mathrm{pH} 8$, in order to obtain concentrations between 0 and $150 \mu \mathrm{g} \mathrm{L}^{-1}$. Afterwards, $0.25 \mathrm{U} \mathrm{mL}^{-1}$ acetylcholinesterase or butyrylcholinesterase were added to each microwell and incubated for $5 \mathrm{~min}$. The reaction was started by the addition of a substrate mixture, composed by equal parts of $3 \mathrm{mM}$ 5,5'-dithiobis[2nitrobenzoic acid] (DTNB) and $75 \mathrm{mM}$ acetylthiocholine iodide (ATChI) for AChE or butyrylthiocholine iodide (BuTChI) for BuChE. The absorbance at $415 \mathrm{~nm}$ was read at $0,150,300$, and $450 \mathrm{~s}$ in a Bio-Rad Model 680 microplate reader (Bio-Rad Laboratories, USA). Enzyme inhibition was determined as the percentage activity of reaction media containing samples and the activity of control without inhibitor. All samples were tested in quadruplicate, the mean $\pm \mathrm{SD}$ determined, and results expressed as $\mathrm{IC}_{50}\left(\mu \mathrm{g} \mathrm{mL}{ }^{-1}\right)$ and also as $\%$ inhibition at the highest concentration tested $\left(150 \mu \mathrm{g} \mathrm{mL}^{-1}\right)$, since it allows comparison between extracts that did not achieve 50\% inhibition but nonetheless present different activities.

\section{In vitro cytotoxicity}

The cytotoxicity against A549 human adenocarcinoma tumor cell line was assessed using the 3-(4,5-dimethylthiazol-2-yl)2,5-diphenyltetrazolium bromide (MTT) assay. Briefly, 96 wells plates were seeded with 20,000 A549 cells per well in
Dulbecco's modified Eagle's medium (DMEM), supplemented with $2 \%$ fetal bovine serum (FBS) and $1 \%$ penicillinstreptomycin mixture $\left(10,000 \mathrm{UI} \mathrm{mL}^{-1}\right)$, in the presence of known concentrations of the extracts or standard previously dissolved in dimethyl sulfoxide (DMSO). The microplates were incubated for $48 \mathrm{~h}$ at $37{ }^{\circ} \mathrm{C}, 5 \% \mathrm{CO}_{2}$, and $98 \%$ humidity. Afterwards, $10 \mu \mathrm{L}$ of $5 \mathrm{mg} \mathrm{mL}^{-1}$ MTT were added and the microplate was again incubated at $37^{\circ} \mathrm{C}$ for 3 to $4 \mathrm{~h}$. The culture medium was removed and DMSO was added to the wells to dissolve formazan crystals. The absorbance was read in a Bio-Rad Model 680 microplate reader at $550 \mathrm{~nm}$. All samples were tested in quadruplicates, the mean \pm SD determined and results were expressed as $\mathrm{IC}_{50}\left(\mu \mathrm{g} \mathrm{mL}^{-1}\right)$ and also as $\%$ inhibition at the highest concentration tested $\left(200 \mu \mathrm{g} \mathrm{mL}^{-1}\right)$, as referred above.

\section{Spectroscopic analysis}

ATR-FTIR spectra of the samples were obtained with a Perkin Elmer Spectrum Two, coupled with a Diamond ATR accessory (DurasamplIR II, Smiths Detection, UK). Thirty-two scans were acquired in transmittance mode in the range of 2000$650 \mathrm{~cm}^{-1}$, with a wavenumber resolution of $1 \mathrm{~cm}^{-1}$. All samples were analyzed in triplicate.

\section{Results}

\section{Lipid screening}

The amounts of total lipids from each algal species and lipid classes separated from the total extracts are presented in Table 1. Total lipids were higher in Z tournefortii $(9.66 \pm$ $\left.0.30 \mathrm{~g}(100 \mathrm{~g})^{-1} \mathrm{dw}\right)$, followed by A. taxiformis $(6.08 \pm$ $\left.0.45 \mathrm{~g}(100 \mathrm{~g})^{-1} \mathrm{dw}\right)$ and $U$. lactuca $\left(1.33 \pm 0.03 \mathrm{~g}(100 \mathrm{~g})^{-1}\right.$ $\mathrm{dw})$. Neutral lipids and sterols were in a similar proportion in the $U$. lactuca and A. taxiformis extracts $(50.63 \pm 6.10$ and $51.16 \pm 4.85 \%$, respectively) and in a lower proportion in $Z$. tournefortii $(26.96 \pm 8.22 \%)$. The glycolipids fraction was between $36.03 \pm 8.08$ and $16.11 \pm 1.36 \%$ in Z. tournefortii and $U$. lactuca, respectively. The phospholipids fraction did not differ much between species, varying from $35.91 \pm 2.36$ to $31.60 \pm 1.40 \%$ in A. taxiformis and Z. tournefortii, respectively.

TLC (thin layer chromatography) was used as a rapid and reliable way to ascertain biochemical differences between these three different macroalgae, screening the presence of neutral lipids (NL), glycolipids (GL), and phospholipids (PL) in the lipid content. TLC results are presented in Table 2 as a presence $(+)$ or absence $(-)$ of similar spots. Qualitative assessment of NL was carried out by comparison using cholesterol acetate, cholesterol, $\beta$-carothene, and phytol standards. The NL of $U$. lactuca and $Z$. tournefortii presented 
Table 1 Total lipid content and class fractionation of Ulva lactuca, Zonaria tournefortii, and Asparagopsis taxiformis

\begin{tabular}{lll}
\hline Sample & & Average \pm standard deviation \\
\hline Ulva lactuca & Total lipids & $1.33 \pm 0.03 \mathrm{~g}(100 \mathrm{~g})^{-1}$ \\
(Chlorophyta) & Neutral and sterols & $50.63 \pm 6.10 \%$ \\
& Glycolipids & $16.11 \pm 1.36 \%$ \\
& Phospholipids & $35.84 \pm 3.40 \%$ \\
Asparagopsis taxiformis (Rhodophyta) & Total lipids & $6.08 \pm 0.45 \mathrm{~g}(100 \mathrm{~g})^{-1} \mathrm{dw}$ \\
& Neutral and sterols & $51.16 \pm 4.85 \%$ \\
& Glycolipids & $23.68 \pm 1.92 \%$ \\
& Phospholipids & $35.91 \pm 2.36 \%$ \\
& Total lipids & $9.66 \pm 0.30 \mathrm{~g}(100 \mathrm{~g})^{-1} \mathrm{dw}$ \\
& Neutral and sterols & $26.96 \pm 8.22 \%$ \\
& Glycolipids & $36.03 \pm 8.08 \%$ \\
& Phospholipids & $31.60 \pm 1.40 \%$ \\
\hline
\end{tabular}

Data for total lipids are mean values \pm standard deviation (SD) in $\mathrm{g}(100 \mathrm{~g})^{-1}$ of dry weight $(\mathrm{dw})$. Lipid class fractionation (neutral and sterols, glycolipids, and phospholipids) are described as percentage (\%) of total lipid content spots with retention factors $\left(R_{\mathrm{f}}\right)$ similar to phytol. Unesterified sterols with an $R_{\mathrm{f}}$ similar to cholesterol was visible in all the macroalgae used in this work but esterified sterol and $\beta$ carothene were not detected. For GL fraction, a spot with the same $R_{\mathrm{f}}$ of digalactosyldiacylglycerol (DGDG) standard was found in $U$. lactuca but not on the other macroalgae. Concerning the phospholipid fraction, standards were L- $\alpha$ phosphatidylcholine (PC), L- $\alpha$-phosphatidylethanolamine (PE), 1-(3-sn-phosphatidyl)-rac-glycerol sodium salt (PG), 1,2-diacyl-sn-glycero-phospho-L-serine (PS), cardiolipin sodium salt (CL), and L- $\alpha$-lysophosphatidylcholine (LPC). Ulva lactuca presented a similar $R_{\mathrm{f}}$ developed by $\mathrm{CL}$ and PC. Asparagopsis taxiformis and $Z$. tournefortii demonstrated similar $R_{\mathrm{f}}$ with PE and PG standards. None of the macroalgae had similar $R_{\mathrm{f}}$ developed by PS and LPC standards.

\section{Fatty acids}

The results concerning fatty acids (FA) with carbon chain from $\mathrm{C} 13$ to $\mathrm{C} 24$ are presented in Table 3. Maximum value of total FA content was determined in Z. tournefortii $(12.32 \pm$ $\left.1.28 \mathrm{mg} \mathrm{g}^{-1}\right)$, followed by U. lactuca $\left(7.54 \pm 0.92 \mathrm{mg} \mathrm{g}^{-1}\right)$ and A. taxiformis $\left(6.01 \pm 0.70 \mathrm{mg} \mathrm{g}^{-1}\right)$. Total SFA were higher in A. taxiformis $\left(5.65 \pm 0.66 \mathrm{mg} \mathrm{g}^{-1}\right)$, comprising about $94 \%$ of total FA, and the remaining being monounsaturated FA (MUFA). The majority of the SFA determined in A. taxiformis were palmitic (16:0) and myristic acid (14:0),
Table 2 Thin layer chromatography (TLC) performed in Ulva lactuca, Zonaria tournefortii, and Asparagopsis taxiformis

\begin{tabular}{lllll}
\hline & Standards & U.lactuca & A.taxiformis & Z. tournefortii \\
\hline Neutral lipids & Cholesterol acetate & - & - & - \\
& Cholesterol & + & + & + \\
& B-carothene & - & - & - \\
Glycolipids & Phytol & + & - & + \\
Phospholipids & DGDG & + & - & - \\
& PC & + & - & + \\
& PE & - & + & + \\
& PG & - & + & - \\
& PS & - & - & - \\
\hline
\end{tabular}

Lipid classes comprising the lipid extract performed according to Folch et al. (1957) methodology, using the LE (lipophilic extract) was performed with $\mathrm{CHCl}_{3}: \mathrm{MeOH}(2: 1)$. The table indicates the presence (+) or absence (-) of similar retention factor $\left(R_{\mathrm{f}}\right)$ spots of the working standards for each lipid classes. Digalactosyldiacylglycerol (DGDG); L- $\alpha$-phosphatidylcholine (PC); L- $\alpha$-phosphatidylethanolamine (PE); 1-(3-sn-phosphatidyl)-rac-glycerol sodium salt (PG); 1,2-diacyl-sn-glycero-phospho-L-serine (PS); cardiolipin sodium salt (CL); L- $\alpha$ lysophosphatidylcholine (LPC) 
Table 3 Fatty acid composition performed by GC-MS in Ulva lactuca, Zonaria tournefortii, and Asparagopsis taxiformis

\begin{tabular}{|c|c|c|c|c|c|c|}
\hline & \multicolumn{2}{|l|}{ U. lactuca } & \multicolumn{2}{|l|}{ Z. tournefortii } & \multicolumn{2}{|l|}{ A. taxiformis } \\
\hline & $\mathrm{mg} \mathrm{g}^{-1}$ & $\%$ of TFA & $\mathrm{mg} \mathrm{g}^{-1}$ & $\%$ of TFA & $\mathrm{mg} \mathrm{g}^{-1}$ & $\%$ of TFA \\
\hline $14: 00$ & $0.07 \pm 0.01$ & $0.95 \pm 0.02$ & $0.76 \pm 0.08$ & $6.14 \pm 0.20$ & $1.14 \pm 0.12$ & $18.82 \pm 0.18$ \\
\hline $16: 00$ & $3.76 \pm 0.41$ & $49.84 \pm 1.00$ & $3.97 \pm 0.47$ & $32.18 \pm 0.57$ & $4.32 \pm 0.52$ & $71.86 \pm 0.25$ \\
\hline 18:00 & $0.07 \pm 0$ & $0.86 \pm 0.02$ & $0.09 \pm 0.01$ & $0.70 \pm 0.03$ & $0.14 \pm 0.02$ & $2.30 \pm 0.02$ \\
\hline 16:01 & $0.41 \pm 0.04$ & $5.40 \pm 0.04$ & $3.30 \pm 0.39$ & $26.77 \pm 0.47$ & $0.04 \pm 0.01$ & $0.72 \pm 0.02$ \\
\hline 18:01 & $1.86 \pm 0.16$ & $24.65 \pm 0.07$ & $2.03 \pm 0.22$ & $16.47 \pm 0.29$ & $0.32 \pm 0.04$ & $5.29 \pm 0.07$ \\
\hline $18: 2 \omega 6$ & $0.32 \pm 0.02$ & $4.23 \pm 0.07$ & n.d. & n.d. & n.d. & n.d. \\
\hline $18: 3 \omega 3$ & $0.43 \pm 0.01$ & $5.73 \pm 0.35$ & n.d. & n.d. & n.d. & n.d. \\
\hline 18:4c3 & $0.35 \pm 0.02$ & $4.60 \pm 0.11$ & $0.65 \pm 0.06$ & $5.24 \pm 0.14$ & n.d. & n.d. \\
\hline 20:4w6 (AA) & n.d. & n.d. & $0.14 \pm 0.01$ & $1.17 \pm 0.11$ & n.d. & n.d. \\
\hline 20:5w3 (EPA) & n.d. & n.d. & $0.32 \pm 0.01$ & $2.59 \pm 0.28$ & n.d. & n.d. \\
\hline $22: 5 \omega 3$ & $0.08 \pm 0.01$ & $1.11 \pm 0.20$ & $0.15 \pm 0.01$ & $1.23 \pm 0.18$ & n.d. & n.d. \\
\hline$\omega 3$ & $0.86 \pm 0.03$ & $11.44 \pm 0.66$ & $1.11 \pm 0.06$ & $9.05 \pm 0.55$ & n.d. & n.d. \\
\hline$\omega 6$ & $0.32 \pm 0.02$ & $4.23 \pm 0.07$ & $0.14 \pm 0.01$ & $1.17 \pm 0.11$ & n.d. & n.d. \\
\hline SFA & $4.09 \pm 0.42$ & $54.28 \pm 0.70$ & $4.95 \pm 0.57$ & $40.13 \pm 0.64$ & $5.65 \pm 0.66$ & $94.00 \pm 0.06$ \\
\hline MUFA & $2.26 \pm 0.20$ & $30.05 \pm 0.08$ & $5.33 \pm 0.61$ & $43.24 \pm 0.43$ & $0.36 \pm 0.04$ & $6.00 \pm 0.006$ \\
\hline PUFA & $1.18 \pm 0.05$ & $15.67 \pm 0.72$ & $2.04 \pm 0.14$ & $16.63 \pm 0.94$ & n.d. & n.d. \\
\hline$\omega 3$ HUFA & $0.08 \pm 0.01$ & $1.11 \pm 0.20$ & $0.47 \pm 0.02$ & $3.81 \pm 0.45$ & n.d. & n.d. \\
\hline Total $\mathrm{mg} \mathrm{g}^{-1}$ & $7.54 \pm 0.92$ & - & $12.32 \pm 1.28$ & - & $6.01 \pm 0.70$ & - \\
\hline$\omega 6 / \omega 3$ Ratio & 0.71 & & 0.13 & & n.d. & \\
\hline IT & 0.59 & & 0.35 & & 30.02 & \\
\hline IA & 1.18 & & 1.06 & & 24.57 & \\
\hline
\end{tabular}

Data presented are mean values \pm standard deviation (SD) of FAME in $\mathrm{mg} \mathrm{g}^{-1}$ of dry weight (DW) or in percentage (\%) of total fatty acids (TFA). AA arachidonic acid, EPA eicosapentaenoic acid, $\omega$ omega, SFA saturated fatty acids, MUFA monounsaturated fatty acids, PUFA polyunsaturated fatty acids, HUFA high unsaturated fatty acids, n.d. not detected, IT index of thrombogenicity, IA index of atherogenicity accounting for almost 72 and $19 \%$ of total FA in this macroalgae. For Z. tournefortii, of the $12.32 \pm 1.28 \mathrm{mg} \mathrm{g}^{-1}$ of FA, approximately $40 \%$ were SFA, $43 \%$ MUFA, and $17 \%$ PUFA. As above, the majority of SFA were palmitic and myristic acid, 32 and $6 \%$ of total FA, respectively. The MUFA were mainly represented by monounsaturated palmitic (16:1) and stearic acid (18:1), accounting for almost 27 and $17 \%$ of total FA, respectively. Concerning the polyunsaturated $\omega 3$ and $\omega 6 \mathrm{FA}$, these were mainly represented by stearidonic

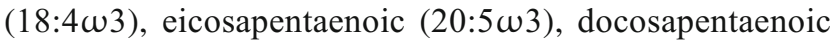

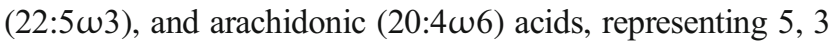
for the former and $1 \%$ for the last two PUFA, respectively. For $U$. lactuca, which contained $7.54 \pm 0.92 \mathrm{mg} \mathrm{g}^{-1}$ of FA, approximately $54 \%$ were SFA, $30 \%$ MUFA, and $16 \%$ PUFA. Again, palmitic acid represented the majority of SFA, accounting for $50 \%$ of total SFA in U. lactuca. The MUFA were mainly represented by the monounsaturated stearic $(25 \%)$ and palmitic acid (5\%). PUFA in U. lactuca were characterized primarily by $\alpha$-linolenic, stearidonic, linoleic, and docosapentaenoic acids, representing $6,5,4$, and $1 \%$, respectively, of total FA in this macroalgae. The $\omega 6 / \omega 3$ ratio was determined and higher values were achieved in $U$. lactuca
(0.71) and Z. tournefortii (0.13). It was not possible to calculate this ratio for A. taxiformis, due to undetermined values for PUFA.

\section{ATR-FTIR analysis}

The three macroalgae studied in this work were assessed using ATR-FTIR analysis (Fig. 1), for comparison between them and to determine the peaks that characterize each of the species. Sixteen important bands were detected from 650 to $2000 \mathrm{~cm}^{-1}$, the transmittance transformed to absorbance and a comparison was carried out. At $790 \mathrm{~cm}^{-1}$ (A) and $846 \mathrm{~cm}^{-1}$ (B), two small peaks were distinguished which could represent the $\mathrm{C}-\mathrm{O}-\mathrm{S}$ vibration in the equatorial position and axial position, respectively. A strong IR band (C) at $1020 \mathrm{~cm}^{-1}$ was detected, indicating a $\mathrm{C}-\mathrm{O}-\mathrm{C}$ bending of polysaccharides constituents. Another peak was detected at $1050 \mathrm{~cm}^{-1}$ (D), representative of $\mathrm{C}-\mathrm{O}-\mathrm{C}$ skeletal vibration and at $1080 \mathrm{~cm}^{-1}$ (E) a vibration of $\mathrm{C}-\mathrm{O}-\mathrm{C}$ structure of polysaccharides. Likewise, a shoulder at $1161 \mathrm{~cm}^{-1}(\mathrm{~F})$ was detected, corresponding to vibration of $\mathrm{C}-\mathrm{O}-\mathrm{C}$ of carbohydrates from polysaccharides. Furthermore, at $1222 \mathrm{~cm}^{-1}(\mathrm{G})$, a medium- 


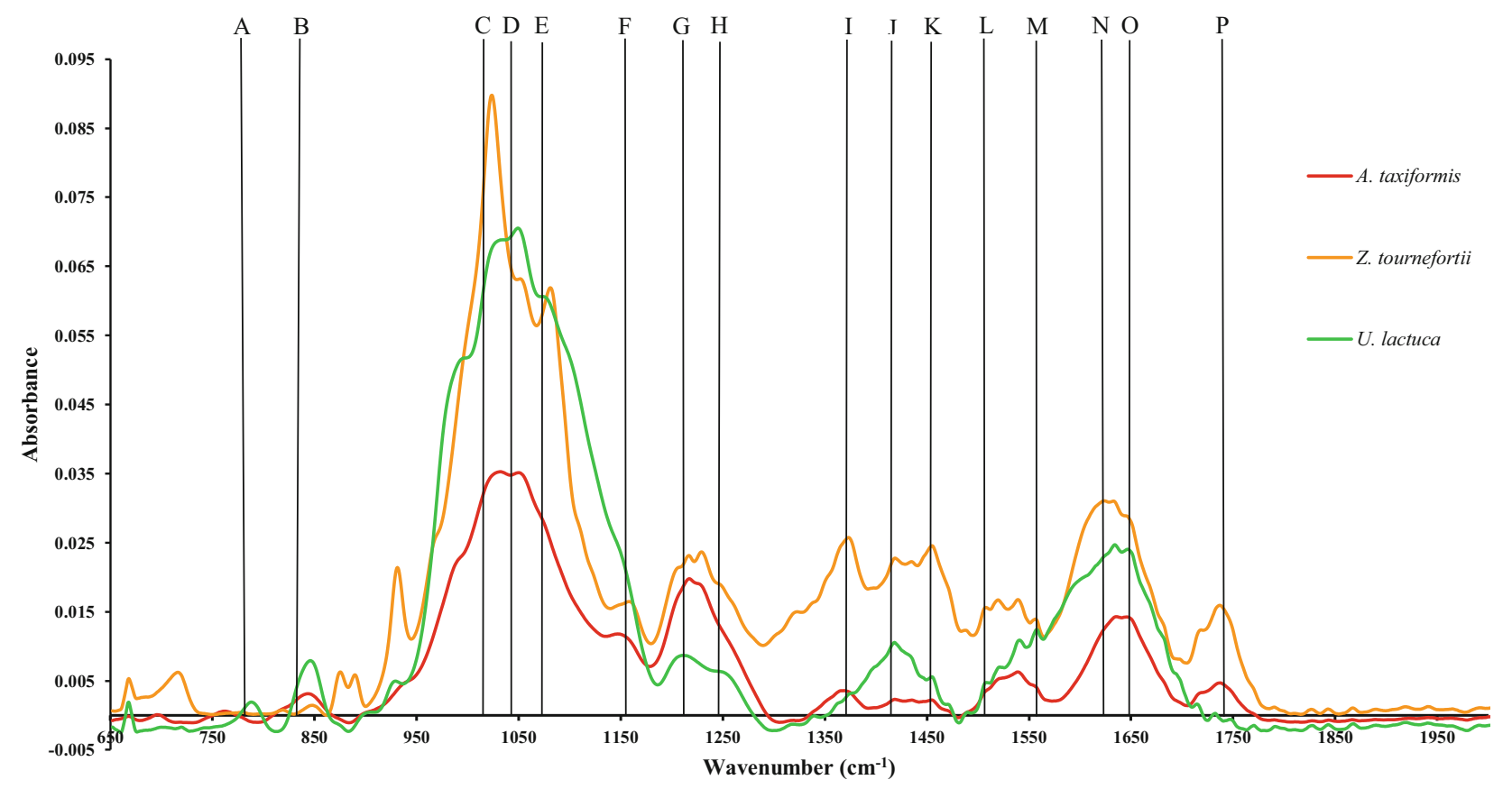

Fig. 1 ATR-FTIR spectra, plotting wavenumber $\left(\mathrm{cm}^{-1}\right)$ by absorbance, for the macroalgae lyophilized with bands from A to P indicating important peaks

intensity $\mathrm{S}=\mathrm{O}$ vibration arouse and a shoulder at $1256 \mathrm{~cm}^{-1}$ $(\mathrm{H})$ which indicates the asymmetric $\mathrm{O}=\mathrm{S}=\mathrm{O}$ stretching vibration of sulphate esters with possibly some contribution of $\mathrm{COH}, \mathrm{CC}$, and $\mathrm{CO}$ vibrations. A medium-intensity peak was visualized at $1375 \mathrm{~cm}^{-1}$ (I), representative of symmetric deformations in $\mathrm{CH}_{2}$ in proteins and $\mathrm{N}\left(\mathrm{CH}_{3}\right)_{3}$ methyl bending in lipids. At $1434 \mathrm{~cm}^{-1}(\mathrm{~J})$, a C-H bending vibration was detected and at $1455 \mathrm{~cm}^{-1}(\mathrm{~K})$, a scissoring vibration of $\mathrm{CH}_{2}$ or/and an asymmetric bending vibration of $\mathrm{CH}_{3}$ of fucose. Between $1510 \mathrm{~cm}^{-1}(\mathrm{~L})$ and $1558 \mathrm{~cm}^{-1}(\mathrm{M})$, four peaks emerged and their presence is attributed to bending vibrations of $\mathrm{N}-\mathrm{H}$ of protein amide II and stretching vibrations of C-N. Similarly, medium-intensity peaks were identified at $1622 \mathrm{~cm}^{-1}(\mathrm{~N})$ and $1648 \mathrm{~cm}^{-1}(\mathrm{O})$, representing the stretching vibrations of $\mathrm{C}=\mathrm{O}$ of protein amide I. At $1739 \mathrm{~cm}^{-1}(\mathrm{P})$, a small intensity peak was observed which corresponds to $\mathrm{C}=\mathrm{O}$ vibration of aldehyde.

\section{Bioactivity}

The anti-acetylcholinesterase (anti-AChE) and antibutyrylcholinesterase (anti-BuChE) activities for the lipophilic extract (LE) extracts and the ethanolic extracts (EE) are presented in Table 4. These extractions were compared to determine the difference in bioactivity when using extracts performed using chloroform and methanol (LE) or a scalable extractor (Timatic) that can be used in the industry with a more environmental friendly solvent, ethanol (EE). The results have shown that LE extracts were more active AChE inhibitors when compared with $\mathrm{EE}$, as seen by the lower $\mathrm{IC}_{50}$ values and/or higher inhibition percentages at $150 \mu \mathrm{g} \mathrm{mL}^{-1}$. The highest activity was found in A. taxiformis extracts, with $\mathrm{IC}_{50}=8.92 \pm 0.43$ and $46.33 \pm 6.02 \mu \mathrm{g} \mathrm{mL}^{-1}$ for $\mathrm{LE}$ and $\mathrm{EE}$, respectively. Concerning BuChE inhibition, once again, A. taxiformis was more active, with $13.96 \pm 0.32$ and $28.1 \mu \mathrm{g} \mathrm{mL}^{-1}$ for LE and EE, respectively. All of these extracts were double cholinesterase inhibitors, except for $U$. lactuca $\mathrm{EE}$, and the high activity of A. taxiformis LE must be highlighted, with low $\mathrm{IC}_{50}$ values and in the case of $\mathrm{BuChE}$ inhibition, almost four-fold more active than Donepezil standard, which is used in the treatment of Alzheimer's disease.

The cytotoxicity in A549 adenocarcinomic human alveolar basal epithelial cells was also assessed, with results presented in Table 5. The $\mathrm{IC}_{50}$ results ranged between $98.02 \pm 0.23$ and $140.42 \pm 4.99 \mu \mathrm{g} \mathrm{mL}^{-1}$, for A. taxiformis LE and EE extracts, respectively.

\section{Discussion}

\section{Total lipids}

The macroalgae analyzed in this work have a low lipid content, which is in agreement with previous works (Paiva et al. 
Table 4 In vitro anticholinesterasic potential of macroalgae extracts

\begin{tabular}{|c|c|c|c|c|}
\hline & \multicolumn{2}{|l|}{ AChE activity } & \multicolumn{2}{|l|}{ BuChE activity } \\
\hline & $\begin{array}{l}\% \text { inhibition } \\
\left(150 \mu \mathrm{gL}^{-1}\right)\end{array}$ & $\begin{array}{l}\mathrm{IC}_{50} \\
\left(\mu \mathrm{g} \mathrm{mL} L^{-1}\right)\end{array}$ & $\begin{array}{l}\% \text { inhibition } \\
\left(150 \mu \mathrm{gL}^{-1}\right)\end{array}$ & $\begin{array}{l}\mathrm{IC}_{50} \\
\left(\mu \mathrm{g} \mathrm{mL} L^{-1}\right)\end{array}$ \\
\hline U. lactuca LE & $37.06 \pm 1.06$ & $>150$ & $16.52 \pm 4.72$ & $>150$ \\
\hline U. lactuca $\mathrm{EE}$ & 0 & $>150$ & 0 & $>150$ \\
\hline Z. tournefortii LE & $42.73 \pm 1.70$ & $>150$ & $19.59 \pm 5.55$ & $>150$ \\
\hline Z. tournefortii EE & $40.12 \pm 4.61$ & $>150$ & $30.81 \pm 3.26$ & $>150$ \\
\hline A. taxiformis LE & 100 & $8.92 \pm 0.43$ & 100 & $13.96 \pm 0.32$ \\
\hline A. taxiformis $\mathrm{EE}$ & 100 & $46.33 \pm 6.02$ & 100 & $28.10 \pm 0.93$ \\
\hline Donepezil & $95.20 \pm 0.40$ & $0.01 \pm 0.00$ & 100 & $55.62 \pm 3.47$ \\
\hline Galantamine & $98.40 \pm 1.50$ & $0.43 \pm 0.09$ & $37.80 \pm 0.90$ & $>150$ \\
\hline
\end{tabular}

For the percentage (\%) of inhibition using the concentration of $150 \mu \mathrm{g} \mathrm{mL} L^{-1}$ of extract, data is presented as $\%$. The $\mathrm{IC}_{50}$ results are presented as the concentration of extract needed, in $\mu \mathrm{g} \mathrm{mL}^{-1}$, to inhibit $50 \%$ of the enzyme. LE (lipophilic extract) indicates that extract was performed with $\mathrm{CHCl}_{3}: \mathrm{MeOH}(2: 1)$. EE (ethanolic extract) indicates that the extract was performed with Timatic extractor using 96\% ethanol. AChE acetylcholinesterase, $\mathrm{BuChE}$ butyrylcholinesterase
2014; Kendel et al. 2015). Ulva lactuca lipid content was 1.33 $\pm 0.03 \mathrm{~g}(100 \mathrm{~g})^{-1} \mathrm{dw}$, which is in the middle of the values range reported by Santos et al. (2015), who obtained $0.3 \mathrm{~g}$ $(100 \mathrm{~g})^{-1} \mathrm{dw}$ U. lactuca produced by aquaculture, and by Khotimchenko et al. (2002), who reported $3.06 \mathrm{~g}(100 \mathrm{~g})^{-1}$ $\mathrm{dw}$ in $U$. lactuca collected in Bodega Bay, California. Therefore, lipid content can be extremely variable in this species, possibly according to environmental differences. Ragonese et al. (2014) also evaluated A. taxiformis collected in the Sicilian coast and determined a lipid yield of $12.22 \mathrm{~g}$ $(100 \mathrm{~g})^{-1} \mathrm{dw}$, roughly twice that we have determined (6.08 \pm $\left.0.45 \mathrm{~g}(100 \mathrm{~g})^{-1} \mathrm{dw}\right)$. The same author analyzed Dictyota dichotoma and the lipid content was found to be less than $Z$. tournefortii, belonging to the same family, these macroalgae contain 6.27 and $9.66 \pm 0.30 \mathrm{~g}(100 \mathrm{~g})^{-1} \mathrm{dw}$, respectively. Burreson et al. (1976) determined 42 different components in the essential oil of $A$. taxiformis, collected in

Table 5 Cytotoxicity effect of macroalgae extracts against A549 tumor cell line

\begin{tabular}{lll}
\hline & $\%$ toxicity $\left(200 \mu \mathrm{g} \mathrm{mL}{ }^{-1}\right)$ & $\mathrm{IC}_{50}\left(\mu \mathrm{g} \mathrm{mL}^{-1}\right)$ \\
\hline U. lactuca $\mathrm{LE}$ & 0 & $>200$ \\
U. lactuca $\mathrm{EE}$ & $90.15 \pm 6.96$ & $140.42 \pm 4.99$ \\
Z. tournefortii $\mathrm{LE}$ & n.d. & n.d. \\
Z. tournefortii EE & $90.41 \pm 1.52$ & $137.64 \pm 7.89$ \\
A. taxiformis $\mathrm{LE}$ & 100 & $98.02 \pm 0.23$ \\
A. taxiformis $\mathrm{EE}$ & $20.14 \pm 5.65$ & $>200$ \\
Colchicine & $71.69 \pm 0.96$ & $2.78 \pm 0.71$ \\
Paclitaxel & $97.44 \pm 0.66$ & $5.96 \pm 0.98$ \\
\hline
\end{tabular}

The $\mathrm{IC}_{50}$ results are presented as the concentration of extract needed, in $\mu \mathrm{g} \mathrm{mL} \mathrm{m}^{-1}$, to inhibit tumor cell viability by $50 \%$. LE (lipophilic extract) performed with $\mathrm{CHCl}_{3}: \mathrm{MeOH}(2: 1)$. EE (ethanolic extract) performed with Timatic extractor using $96 \%$ ethanol. n.d. not determined
Hawaii, and the bromoform $\mathrm{CHBr}_{3}$, used in the past as a sedative, is the major constituent. It was also stated that although being the favorite edible macroalgae in Hawaii archipelago, the existence of haloforms and halogenated compounds in its essential oil could mean that this macroalgae could be poisonous when consumed. It was not possible to compare results concerning lipid classes with other published works, since few reports exist assessing these lipid groups in these macroalgae. The most similar work is that of Kendel et al. (2015), who evaluated $U$. armoricana and determined that NL was $55.60 \%$ (ours $50.63 \%$ ), GL was $29.10 \%$ (ours $16.11 \%$ ), and PL is $15.30 \%$ (ours $35.11 \%$ ). Comparing these results, we can determine that these lipid classes yield varies significantly, even for macroalgae of the same genus.

The TLC analysis performed for each lipid class revealed that $U$. lactuca lipid composition could contain phytol and a type of cholesterol compound in its NL also revealed the same spots $R_{\mathrm{f}}$ as DGDG in its GL and developed similar $R_{\mathrm{f}}$ to cardiolipin and L- $\alpha$-phosphatidylcholine in its PL. Phytol is a remarkable compound due to its use as a precursor of industrial synthesis of vitamins $\mathrm{E}$ and $\mathrm{K}$ (Kendel et al. 2015). The Z tournefortti also revealed in its NL classes similar $R_{\mathrm{f}}$ presented by phytol and cholesterol and the PL classes contain similar $R_{\mathrm{f}}$ presented by L- $\alpha$-phosphatidylethanolamine and 1-(3-sn-phosphatidyl)-racglycerol. The A. taxiformis revealed similar spots with an $R_{\mathrm{f}}$ similar to cholesterol in its NL fraction and spots with similar $R_{\mathrm{f}}$ presented by phospholipids in $Z$. tournefortii $\mathrm{PL}$ fraction. Ragonese et al. (2014) assessed these classes in 8 macroalgae ( 2 green, 2 red, and 4 brown) and determined that $U$. rigida revealed also analogous spots with an $R_{\mathrm{f}}$ similar to L- $\alpha$-phosphatidylcholine. The same author determined that some species of red and brown macroalgae also present spots with the same $R_{\mathrm{f}}$ as presented by L- $\alpha$-phosphatidylethanolamine and $1-(3-\mathrm{s} n-$ phosphatidyl)-rac-glycerol. 


\section{Fatty acids}

The FA yield in this work was higher in Z. tournefortii (1.23\% $\mathrm{dw})$, followed by $U$. lactuca $(0.75 \% \mathrm{dw})$ and A. taxiformis $(0.6 \% \mathrm{dw})$. Schmid et al. (2018) evaluated 61 species of macroalgae collected along the Southern Australian shore and also determined the TFA for the Dictyopteris muelleri, from the same family that $Z$. tournefortii (Dictyotaceae). The TFA varied from 1.6 to $4.8 \%$, for $Z$. turneriana and D. muelleri, respectively. This author also determined for Ulva a variation between 0.5 to $1.9 \%$ of TFA and for the Ptilonia australasica and Delisea pulchra, belonging to the same family as A. taxiformis (Bonnemaisoniaceae), $0.9 \%$ and $2.2 \%$, respectively. Our values agree with or were close to the reported values, with some discrepancy due to environmental factors such as availability of nutrients in seawater, light availability, herbivory pressure, seasonal period of harvest, and geographical location.

Highest amount of SFA was detected in the red alga A. taxiformis, $94 \%$ of total FA of which $72 \%$ is comprised by palmitic acid (C16:0). This result does not agree with of Mellouk et al. (2017), who reported $23.7 \%$ of SFA and $67.8 \%$ of unsaturated fatty acids (UFA) for the same species, from the Mediterranean, near the Algerian coast. This enormous difference is not easy to explain, although it is probably due to environmental differences between the Mediterranean and the open Atlantic Ocean, such as water temperature and hydrodynamism. It also raises the need to assess nutritional profiles of macroalgae collected in different locations and possibly also at different phases of the life cycle. Gressler et al. (2010) determined that SFA varied from 51 to $78 \%$ and palmitic acid is the most representative SFA in four species of red macroalgae, collected in the intertidal zone of Anchieta, Espírito Santo State, Brazil. SFA composition of Z. tournefortii $(40 \%)$ and D. muelleri (39\%) was similar (Schmid et al. 2018). The FA composition of the chlorophyte $U$. lactuca subjected to different environments was analyzed. For instance, Cardoso et al. (2017) evaluated this macroalgae cultivated in fish ponds and demonstrated that SFA were lower (38\%) when comparing with our results (54\%) with palmitic acid (16:0) accounting for $19 \%$ and 50\% of total FA, respectively. Mai et al. (1994) assessed the nutritional quality of $U$. lactuca for the nutrition of two species of abalone pointing out that palmitic acid (24\%) is a major component of FA fraction in $U$. lactuca. The assessment of $U$. lactuca collected by Verma et al. (2017) from the intertidal zone, in Port Okha (Gujarat), India, also revealed high yield of this SFA (31\%). Kendel et al. (2015) evaluated two macroalgae, Ulva armoricana and Solieria chordalis, from Brittany (France) and determined that palmitic acid was predominant in these macroalgae. Furthermore, Sánchez-Machado et al. (2004) evaluated 5 edible macroalgae, Himanthalia elongata, Laminaria ochroleuca, Undaria pinnatifida, Palmaria sp., and Porphyra sp., along the northwest Iberian Coast, whereas the SFA varies from 20.39 to $64.95 \%$, and palmitic acid being again the major FA, with values between 16.51 until $63.19 \%$ of total FA.

The highest value of MUFA was detected in the Z. tournefortii (43.27\%), followed by U. lactuca (30.04\%) and A. taxiformis (6.01\%). The most prominent FA among MUFA changed between species, since in $U$. lactuca and A. taxiformis was the stearic acid, with 24.65 and $5.29 \%$, respectively, whilst in $Z$. tournefortii, the major concentration of MUFA was palmitic acid, corresponding to $26.80 \%$ of total FA. Cardoso et al. (2017) determined to be the most representative MUFA (16.6\%) in U. lactuca, collected from fish ponds, the stearic acid with $7.7 \%$ of total FA. Dawczynski et al. (2007) determined that MUFA content varies between 7.8 and $20.7 \%$ in 4 dried edible macroalgae Porphyra sp., U. pinnatifida, Laminaria sp., and Halymenia fusiforme, with stearic acid being the most representative, varying from 5.95 to $15.3 \%$ of total FA.

The highest content of PUFA was determined in Z. tournefortii, $2.04 \pm 0.14 \mathrm{mg} \mathrm{g}^{-1} \mathrm{dw}$ (16.58\% of TFA), followed by $U$. lactuca with $1.18 \pm 0.05 \mathrm{mg} \mathrm{g}^{-1} \mathrm{dw}$ (15.62\% of TFA), whilst no PUFA was detected in A. taxiformis. SánchezMachado et al. (2004) determined that PUFA content varies between 16.10 and $69.11 \%$ in edible macroalgae, with our values close to the lowest assessed content. The most representative PUFA was determined to be species dependent. In $U$. lactuca, the $\alpha$-linolenic acid, $0.43 \pm 0.01 \mathrm{mg} \mathrm{g}^{-1} \mathrm{dw}$ (5.71\% of TFA), and Z. tournefortii the stearidonic acid, 0.65 $\pm 0.06 \mathrm{mg} \mathrm{g}^{-1} \mathrm{dw}$ (5.24\% of TFA), are the main PUFA components. According to several scientific reports, the most representative PUFA in seaweed appears to be variable. Cardoso et al. (2017) and Wahbeh (1997) refer that linoleic acid is the principal PUFA in U. lactuca, composing 9.5 and 9.7\%, respectively. On the other hand, Mai et al. (1994) determined that stearidonic acid was the most representative PUFA in U. lactuca (14.8\%). Verma et al. (2017), studying this macroalgae, determined that $\alpha$ linolenic acid was the major PUFA, coinciding with our finding, but with higher $14.31 \%$ in the TFA. The eicosanoid precursor, arachidonic acid, $0.14 \pm 0.01 \mathrm{mg} \mathrm{g}^{-1} \mathrm{dw}$ (1.16\% of TFA), and eicosapentaenoic acid, having $0.32 \pm 0.01 \mathrm{mg} \mathrm{g}^{-1} \mathrm{dw}(2.57 \%$ of TFA), were only determined in Z. tournefortii. SánchezMachado et al. (2004) also demonstrated that the most representative PUFA is also macroalgae dependent, with arachidonic acid having the highest content in Porphyra sp. (6.80\%), H. elongata (10.69\%), and L. ochroleuca (14.20\%). Stearidonic acid is present in $U$. pinnatifida with $22.60 \%$ and the eicosapentaenoic acid in E Palmaria sp. with $24.05 \%$. These different observations allow us to conclude that the major macroalgae FA content is seasonal dependent, and will vary depending on the geographical location and ecosystem dynamics. This conclusion is supported by dependent Nelson et al. (2002) and Polat and Ozogul (2013). 
The $\omega 6 / \omega 3$ ratio in $U$. lactuca was 0.71 and in Z. tournefortii 0.13 , with no amount of PUFA detected in A. taxiformis. Sánchez-Machado et al. (2004) determined that this ratio varies from 0.13 to 1.21 in 5 edible macroalgae, Cardoso et al. (2017) determined a 0.86 ratio for $U$. lactuca grown in fish aquaculture ponds and Schmid et al. (2018) establish a 0.8 ratio for $Z$. turneriana collected in the Australian southern shore. It is currently accepted that human beings evolved with a $\omega 6 / \omega 3$ ratio diet of approximately 1 , but nowadays the western diets are between $15 / 1$ and 16.7/1 ratios, whereas a maximum of $4 / 1$ ratio is considered suitable to maintain a healthy status (Simopoulos 2002).. Elevated $\omega 6 /$ $\omega 3$ ratio increase the prostanoid thromboxane $\left(\mathrm{TXA}_{2}\right)$ and inhibit prostacyclin $\left(\mathrm{PGI}_{2}\right)$ production which is linked to the increasing risk of thrombosis (Ulbricht and Southgate 1991). Moreover, Simopoulos (2002) described in his work that a $\omega 6$ rich diet could increase blood viscosity, vasospasm, and vasoconstriction, when a higher consumption of $\omega 3$ helps the relaxation of large arteries and vessels, due to an increase of nitric oxide, an endothelium-derived relaxing factor (EDRF), thus decreasing the atherogenicity effect. Ulbricht and Southgate (1991) developed two interesting equations, one for calculating an index of thrombogenicity (IT) and an index of atherogenicity (IA), where values indicate healthier results. For the macroalgae included in this work, the IT was 0.35 for Z. tournefortii, 0.59 for U. lactuca, and 30.02 for A. taxiformis. These results indicate an anti-thrombogenic effect of $Z$. tournefortii and $U$. lactuca, but due to the absence of PUFA in A. taxiformis, this macroalga appears unsuitable for this purpose. In addition, the toxicity of halogenated compounds in this alga should be pointed out (e.g., Li et al. 2016). For IA, the values were 1.06 for $Z$. tournefortii, 1.18 for U. lactuca, and 24.57 for A. taxiformis. These results evidence an anti-atherogenicity effect of $Z$. tournefortii and $U$. lactuca, whilst $A$. taxiformis is confirmed as unsuitable for this purpose. Vizetto-Duarte et al. (2015) determined these indices in six different Cystoseira species and determined IT values varying between 0.54 and 1.61, and IA between 0.67 and 1.94. Belattmania et al. (2018) also analyzed brown macroalgae from Morocco and determined IT to vary between 0.04 to 0.25 and IA from 0.55 to 1.35 .

These results strongly enforce the possibility of using $U$. lactuca and $Z$. tournefortii lipids to enhance the nutraceutical characteristics of food products and to develop macroalgaebased supplements to improve or maintain health. Considering the above, including $U$. lactuca and $Z$. tournefortii in human nutrition could be a means to reduce the $\omega 6 / \omega 3$ ratio.

\section{ATR-FTIR}

This technique is extensively used for the recognition and characterization of numerous types of molecules, using the fact that it delivers an exclusive signature to each compound.
The transmittance variance detected by the equipment in each wavenumber is due to the relative mass and geometry of the atoms in the sample. The conformation of the molecules enables resonance between vibrations that will modulate the spectra (Derenne et al. 2014). The assessment of our samples allowed distinguishable ATR-FTIR "fingerprints" to be obtained, and two small peaks, most prominent in U. lactuca, with $790 \mathrm{~cm}^{-1}$ (A) and $846 \mathrm{~cm}^{-1}$ (B), according to Robic et al. (2009), indicate the presence of ulvans. These complex polysaccharides are integrated in the cell wall and due to their unusual composition and structure considered a functional biopolymer (Lahaye and Robic 2007). Three welldistinguished peaks and one shoulder located between 1000 and $1200 \mathrm{~cm}^{-1}(\mathrm{C}, \mathrm{D}, \mathrm{E}$, and F) indicate the vibration of sugar rings, overlapping with stretching vibrations of $\mathrm{C}-\mathrm{OH}$ side groups and the $\mathrm{C}-\mathrm{O}-\mathrm{C}$ glycosides bonds. According to Robic et al. (2009), ulvan extracts present strong absorption at $1055 \mathrm{~cm}^{-1}$, close to our D peak at $1050 \mathrm{~cm}^{-1}$. This is well distinguished for $U$. lactuca, due to $\mathrm{C}-\mathrm{O}$ stretching in rhamnose and glucuronic acid. A medium-intensity peak at $1222 \mathrm{~cm}^{-1}(\mathrm{G})$ and $1256 \mathrm{~cm}^{-1}(\mathrm{H})$ was detected in the three macroalgae, indicating polysaccharides with some degree of sulfation. Generally, sample sulfation intensity is detected between 1210 and $1260 \mathrm{~cm}^{-1}$ (Gómez-Ordóñez and Rupérez 2011). In green macroalgae this would be represented by ulvans, in red macroalgae by carrageenans, and for brown macroalgae by fucoidan. These polysaccharides are valuable for their intrinsic rheological qualities (carrageenans) or for their bioactive properties (ulvans and fucoidan). For example, fucoidan, a fucose-enriched sulfated polysaccharide with a high degree of complexity, is described as a compound with anti-inflammatory, anticoagulant, antithrombotic, and antioxidant properties (Senthilkumar et al. 2013) and is exploited as an additive in some products for health food, drinks, and cosmetics (Pádua et al. 2015). These biological properties will vary, depending on the density and specific positions of these sulfated groups (Berteau and Mulloy 2003).

\section{Bioactivity}

Anti-acetylcholinesterasic activity was higher for LE when compared with $\mathrm{EE}$, which can be seen by the lower $\mathrm{IC}_{50}$ results and/or the higher \% inhibition at the highest concentration tested. These results suggest that the molecules responsible for this effect are either lipids or similar compounds. The macroalgae A. taxiformis stands out, presenting 100\% inhibition using $150 \mu \mathrm{g} \mathrm{mL}^{-1}$ for both types of extract and the lowest $\mathrm{IC}_{50}$ results $\left(8.92 \pm 0.43 \mu \mathrm{g} \mathrm{mL}^{-1}\right)$ using LE extract. The EE of this macroalgae also delivered good results, with an $\mathrm{IC}_{50}$ of $46.33 \pm 6.02 \mu \mathrm{g} \mathrm{mL}{ }^{-1}$. For comparison, two widely used drugs in Alzheimer's patients were used in this work: donepezil, a piperidine derivative, and galantamine, an alkaloid. Although the activity shown by these compounds was 
much stronger, it must be pointed out that the activities of the LE and EE $A$. taxiformis extracts, which are mixtures containing a high variety of compounds, are nonetheless high enough to justify a purification to identify the active molecules. These results are far higher than those presented by Stirk et al. (2007), who evaluated 7 macroalgae species from the east coast of South Africa determining the $\mathrm{IC}_{50}$ results for $\mathrm{AChE}$ inhibitory activity. The best result obtained by those authors $\left(\mathrm{IC}_{50}\right.$ of $4800 \mu \mathrm{g} \mathrm{mL}^{-1}$ for Dictyota humifusa) is more than 500 times less active than the $A$. taxiformis EE presented herein. The most interesting result reported by Stirk et al. (2007) is the effect of seasonality on the activity, which may be due to differences in environmental pressures such as predation along the year cycle. The work of these authors point out the need to carry out studies determining the best phase of the algal cycle to collect biomass with significant bioactivity.

Most of the extracts tested also inhibited butyrylcholinesterase, and once again A. taxiformis was most prominent, with LE approximately two-fold more active than EE. In addition, the dual inhibitory activity of $\mathrm{AChE}$ and $\mathrm{BuChE}$ is quite positive, since there is evidence that compounds with this feature can intensify the effectiveness of AD treatment, possibly by also reducing the formation of $\beta$-amyloid plaques (Giacobini 2003).

Overall, the results obtained further reinforce the potential of A. taxiformis extracts for further studies to inhibit these enzymes, since they are much stronger than results reported by other authors for macroalgae extracts. Cystoseira species extracts (Custódio et al. 2016) have a dual AChE and BuChe inhibition, but at much higher concentrations (between 1000 and $\left.10,000 \mu \mathrm{g} \mathrm{mL}^{-1}\right)$ than the ones used herein $(0.293$ and $150 \mu \mathrm{g} \mathrm{mL}^{-1}$ ). What is mentioned above for AChE inhibition is also true for $\mathrm{BuChE}$, i.e., that the compounds with higher anti-cholinesterasic activity are probably lipids or compounds with a similar polarity, since LE extracts were consistently better inhibitors of both enzymes. To avoid the use of chloroform, the ethanolic extraction (EE) could be optimized to effectively extract these compounds, varying the time and number of compression and decompression cycles. These parameters enable the variable pressure for solvent recirculation through the sample. Solvent mixtures could also be applied, adding ethyl acetate, an extensively used solvent in the food industry to decrease polarity. This effort is necessary to develop "greener" methodologies to produce extracts comprising of apolar extracts that could perform equally, efficient reducing the usage of toxic solvents, known to be harmful to the environment.

The cytotoxicity against A549 tumor cell line does not present a clear activity pattern as in the case of anticholinesterasic activities. The A. taxiformis LE, $Z$. tournefortii $\mathrm{EE}$, and $U$. lactuca $\mathrm{EE}$ were the most active extracts, with $\mathrm{IC}_{50}$ values of $98.02 \pm 0.23,137.64 \pm 7.89$, and $140.42 \pm 4.99 \mu \mathrm{g} \mathrm{mL}^{-1}$, respectively. Asparagopsis taxiformis LE again exhibited the best results, highlighting the bioactive potential of this macroalgae and extract for further compound purification. These values are comparable with others reports of activity against this cell line, such as the $\mathrm{IC}_{50}$ of $110 \mu \mathrm{g} \mathrm{mL}^{-1}$ obtained by Dellai et al. (2013), using Laurencia obtusa $\mathrm{MeOH}: \mathrm{CHCl}_{3}$ extracts. Kang et al. (2017) obtain an $\mathrm{IC}_{50}$ of $50 \mu \mathrm{g} \mathrm{mL}^{-1}$ against A549 cells, inducing apoptosis, using Gracilariopsis lemaneiformis. However, this result corresponds to purified polysaccharides and is therefore not comparable with the extracts presented here, since they were extracted with distilled water. Additionally, an Ecklonia cava ethyl acetate extract displayed in vitro metastatic activity against A549 cells, although it did not affect cell viability (Lee et al. 2011). These results suggest that aqueous and fractions of intermediate polarity may also have anticancer potential and should also be investigated. Concerning the results presented herein, the extracts and/or isolated compounds isolated thereof will be tested against other cell lines, namely obtained from non-tumor origin, and the mechanism of toxicity will be assessed. However, in a preliminary study, cytotoxicity against a cell line is a good indicator of potential for further studies using a bioassay guided approach.

\section{Conclusion}

The macroalgae analyzed in the present work present interesting characteristics that justify further research. Ulva lactuca and $Z$. tournefortii have qualities that point out their interest in nutrition, such as their low lipid content and favorable IT and IA values. The presence of polysaccharides such as ulvans or fucoidans with some degree of sulfation, as indicated by ATRFTIR results, also points out the interest of these two macroalgae as staple food, if not for human consumption, a least in animal feed. Concerning A. taxiformis, the high percentage of SFA and the extremely high IA and IT values and other studies which point out to the toxicity of its halogenated compounds do not recommend it as an edible macroalgae, but it displays biological activities that indicate its pharmaceutical interest. The low $\mathrm{IC}_{50}$ values for anti-cholinesterasic activity, particularly those for the LE extract, and the fact that both A. taxiformis extracts present dual $\mathrm{AChE}$ and $\mathrm{BuChE}$ inhibition, are good indicators of the possibility of finding a good candidate scaffold for an anti-Alzheimer Disease drug.

Acknowledgments The authors present their acknowledgment to DRCT (Azores Regional Government) for co-financing, the Portuguese National Funds, through FCT-Fundação para a Ciência e a Tecnologia, and as applicable co-financed by the FEDER within the PT2020 Partnership Agreement by funding the cE3c centre (UID/BIA/00329/2013), (UID/ BIA/00329/2019) and to DRCT for funding Azorean Biodiversity Group (ABG).

Funding information This work was financially supported by DemoBlueAlgae "Desenvolvimento de metodologias e optimização dos processos de cultivo e processamento de macroalgas para a indústria e economia azul" PROCiência 2020 (M1420-01-0247-FEDER000002); 
MACBIOBLUE "Proyecto demostrativo y de transferencia tecnológica para ayudar a las empresas a desarrollar nuevos produtos y procesos en el ambito de la Biotecnología Azul de la Macaronesia" (MAC/1.1b/ 086), program Interreg MAC 2014-2020; ARDITI - Regional Agency for the Development of Research Technology and Innovation (M14-20-095369-FSE-000001-Doctorate in Business; Blue Iodine II "Boost Blue economy through market uptake an innovative seaweed bioextract for iodine fortification II", grant agreement no. 733552, H2020-SMEInst2016-2017.

\section{References}

Albert CM, Hennekens CH, O’Donnell CJ, Ajani UA, Carey VJ, Willett WC, Ruskin JN, Manson JE (1998) Fish consumption and risk of sudden cardiac death. J Am Med Assoc 279:23-28

Alwarsamy M, Gooneratne R, Ravichandran R (2016) Effect of fucoidan from Turbinaria conoides on human lung adenocarcinoma epithelial (A549) cells. Carbohydr Polym 152:207-213

Arruda M, Viana H, Rainha N, Neng NR, Rosa JS, Nogueira JM, Barreto MC (2012) Anti-acetylcholinesterase and antioxidant activity of essential oils from Hedychium gardnerianum Sheppard ex Ker-Gawl. Molecules 17:3082-3092

Barbosa M, Valentão P, Andrade PB (2014) Bioactive compounds from macroalgae in the new millennium: implications for neurodegenerative diseases. Mar Drugs 12:4934-4972

Belattmania Z, Engelen AH, Pereira H, Serrao H, Custodio EA, Varela JC, Zrid R, Reani A, Sabour B (2018) Fatty acid composition and nutraceutical perspectives of brown seaweeds from the Atlantic coast of Morocco. Int Food Res J 25:1520-1527

Berteau O, Mulloy B (2003) Sulfated fucans, fresh perspectives: structures, functions, and biological properties of sulfated fucans and an overview of enzymes active toward this class of polysaccharide. Glycobiology 13:29R-40R

Burreson BJ, Moore RE, Roller PP (1976) Volatile halogen compounds in the alga Asparagopsis taxiformis (Rhodophyta). J Agric Food Chem $24: 856-861$

Cardoso C, Ripol A, Afonso C, Freire M, Varela J, Quental-Ferreira H, Pousão-Ferreira P, Bandarra N (2017) Fatty acid profiles of the main lipid classes of green seaweeds from fish pond aquaculture. Food Sci Nutr 5:1186-1194

Cohen Z, Vonshak A, Richmond A (1988) Effect of environmental conditions on fatty acid composition of the red alga Porphyridium cruentum: correlation to growth rate. J Phycol:328-332

Colovic MB, Krstic DZ, Lazarevic-Pasti TD, Bondzic AM, Vasic VM (2013) Acetylcholinesterase inhibitors: pharmacology and toxicology. Curr Neuropharmacol 11:315-335

Custódio L, Silvestre L, Rocha MI, Rodrigues MJ, Vizetto-Duarte C, Pereira H, Barreira L, Varela J (2016) Methanol extracts from Cystoseira tamariscifolia and Cystoseira nodicaulis are able to inhibit cholinesterases and protect a human dopaminergic cell line from hydrogen peroxide-induced cytotoxicity. Pharm Biol 54: $1687-1696$

Dawczynski C, Schubert R, Jahreis G (2007) Amino acids, fatty acids, and dietary fibre in edible seaweed products. Food Chem 103:891899

Dellai A, Laajili S, Le Morvan V, Robert J, Bouraoui A (2013) Antiproliferative activity and phenolics of the Mediterranean seaweed Laurencia obusta. Ind Crop Prod 47:252-255

Derenne A, Vandersleyen O, Goormaghtigh E (2014) Lipid quantification method using FTIR spectroscopy applied on cancer cell extracts. Biochim Biophys Acta - Mol Cell Biol Lipids 1841:12001209
Ellman GL, Courtney KD, Andres V, Featherstone RM (1961) A new and rapid colorimetric determination of acetylcholinesterase activity. Biochem Pharmacol 7:88-95

Folch J, Lees M, Stanley GHS (1957) A simple method for the isolation and purification of total lipides from animal animal tissues. J Biol Chem 226:497-509

Giacobini E (2003) Cholinesterases : new roles in brain function and in Alzheimer's disease. Neurochem Res 28:515-522

Gómez-Ordóñez E, Rupérez P (2011) FTIR-ATR spectroscopy as a tool for polysaccharide identification in edible brown and red seaweeds. Food Hydrocoll 25:1514-1520

Gressler V, Yokoya NS, Fujii MT, Colepicolo P, Filho JM, Torres RP, Pinto E (2010) Lipid, fatty acid, protein, amino acid and ash contents in four Brazilian red algae species. Food Chem 120:585-590

Gutiérrez-Rodríguez AG, Juárez-Portilla C, Olivares-Bañuelos T, Zepeda RC (2018) Anticancer activity of seaweeds. Drug Discov Today 23: 434-447

Hoffman DR, Boettcher JA, Diersen-Schade DA (2009) Toward optimizing vision and cognition in term infants by dietary docosahexaenoic and arachidonic acid supplementation: a review of randomized controlled trials. Prostaglandins Leukot Essent Fatty Acids 81:151-158

Holdt SL, Kraan S (2011) Bioactive compounds in seaweed: functional food applications and legislation. J Appl Phycol 23:543-597

Howes MR, Perry NSL, Houghton PJ (2003) Plants with traditional uses and activities, relevant to the management of Alzheimer's disease and other cognitive disorders. 18:1-18

Kang Y, Wang ZJ, Xie D, Sun X, Yang W, Zhao X, Xu N (2017) Characterization and potential antitumor activity of polysaccharide from Gracilariopsis lemaneiformis. Mar Drugs 15. https://doi.org/ 10.3390/md15040100

Kendel M, Wielgosz-Collin G, Bertrand S, Roussakis C, Bourgougnon N, Bedoux G (2015) Lipid composition, fatty acids and sterols in the seaweeds Ulva armoricana and Solieria chordalis from Brittany (France): an analysis from nutritional, chemotaxonomic, and antiproliferative activity perspectives. Mar Drugs 13:5606-5628

Khotimchenko SV, Vaskovsky VE, Titlyanova TV (2002) Fatty acids of marine algae from the Pacific coast of North California. Bot Mar 45: $17-22$

Kiso Y (2011) Pharmacology in health foods: effects of arachidonic acid and docosahexaenoic acid on the age-related decline in brain and cardiovascular system function. J Pharmacol Sci 115:471-475

Lahaye M, Robic A (2007) Structure and function properties of ulvan, a polysaccharide from green seaweeds. Biomacromolecules 8:17651774

Lee H, Kang C, Jung E, Kim JS, Kim E (2011) Antimetastatic activity of polyphenol-rich extract of Ecklonia cava through the inhibition of the Akt pathway in A549 human lung cancer cells. Food Chem 127: 1229-1236

Lemke SL, Maki KC, Hughes G, Taylor ML, Krul ES, Goldstein DA, Su H, Rains TM, Mukherjea R (2013) Consumption of stearidonic acid-rich oil in foods increases red blood cell eicosapentaenoic acid. J Acad Nutr Diet 113:1044-1056

Lepage G, Roy CC (1986) Direct transesterification of all classes of lipids in a one-step reaction. Notes Methodol 27:114-120

Li X, Norman HC, Kinley RD, Laurence M, Wilmot M, Bender H, de Nys R, Tomkins N (2016) Asparagopsis taxiformis decreases enteric methane production from sheep. Anim Prod Sci 58:681-688

Mai K, Mercer JP, Donlon J (1994) Comparative studies on the nutrition of two species of abalone, Haliotis tuberculata $\mathrm{L}$ and Haliotis discus hannai Ino. Aquaculture 128:115-130

Marudhupandi T, Ajith Kumar TT, Lakshmanasenthil S, Suja G, Vinothkumar T (2015) In vitro anticancer activity of fucoidan from Turbinaria conoides against A549 cell lines. Int J Biol Macromol 72:919-923

Mattson MP (2004) Pathways towards and away from Alzheimer's disease. Nature 430:631-639 
Mellouk Z, Benammar I, Krouf D, Goudjil M, Okbi M, Malaisse W (2017) Antioxidant properties of the red alga Asparagopsis taxiformis collected on the North West Algerian coast. Exp Ther Med 13:3281-3290

Mišurcová L, Ambrožová J, Samek D (2011) Seaweed lipids as nutraceuticals. In: Kim S-K, Taylor S (eds) Advances in food and nutrition research marine medicinal foods: implications and applications, macro and microalgae. Elsevier, London, pp 339-355

Miyashita K, Mikami N, Hosokawa M (2013) Chemical and nutritional characteristics of brown seaweed lipids: a review. J Funct Foods 5: $1507-1517$

Nelson MM, Phleger CF, Nichols PD (2002) Seasonal lipid composition in macroalgae of the northeastern Pacific Ocean. Bot Mar 45:58-65

Pádua D, Rocha E, Gargiulo D, Ramos AA (2015) Bioactive compounds from brown seaweeds: Phloroglucinol, fucoxanthin and fucoidan as promising therapeutic agents against breast cancer. Phytochem Lett 14:91-98

Paiva L, Lima E, Patarra RF, Neto AI, Baptista J (2014) Edible Azorean macroalgae as source of rich nutrients with impact on human health. Food Chem 164:128-135

Polat S, Ozogul Y (2013) Seasonal proximate and fatty acid variations of some seaweeds from the northeastern Mediterranean coast. Oceanologia 55:375-391

Ragonese C, Tedone L, Beccaria M, Torre G, Cichello F, Cacciola F, Dugo P, Mondello L (2014) Characterisation of lipid fraction of marine macroalgae by means of chromatography techniques coupled to mass spectrometry. Food Chem 145:932-940

Robic A, Bertrand D, Sassi JF, Lerat Y, Lahaye M (2009) Determination of the chemical composition of ulvan, a cell wall polysaccharide from Ulva spp. (Ulvales, Chlorophyta) by FT-IR and chemometrics. J Appl Phycol 21:451-456

Sánchez-Machado DI, López-Cervantes J, López-Hernández J, PaseiroLosada P (2004) Fatty acids, total lipid, protein and ash contents of processed edible seaweeds. Food Chem 85:439-444
Santos SA, Vilela C, Freire CS, Abreu MH, Rocha SM, Silvestre AJ (2015) Chlorophyta and rhodophyta macroalgae: a source of health promoting phytochemicals. Food Chem 183:122-128

Schmid M, Kraft LGK, van der Loos LM, Kraft GT, Virtue P, Nichols PD, Hurd CL (2018) Southern Australian seaweeds: a promising resource for omega-3 fatty acids. Food Chem 265:70-77

Senthilkumar K, Manivasagan P, Venkatesan J, Kim SK (2013) Brown seaweed fucoidan: biological activity and apoptosis, growth signaling mechanism in cancer. Int J Biol Macromol 60:366-374

Simopoulos AP (2002) The importance of the ratio of omega-6/omega-3 essential fatty acids. Biomed Pharmacother 56:365-379

Stirk WA, Reinecke DL, Van Staden J (2007) Seasonal variation in antifungal, antibacterial and acetylcholinesterase activity in seven South African seaweeds. J Appl Phycol 19:271-276

Ulbricht TLV, Southgate DAT (1991) Coronary heart disease: seven dietary factors. Lancet 338:985-992

Verma P, Kumar M, Mishra G, Sahoo D (2017) Multivariate analysis of fatty acid and biochemical constitutes of seaweeds to characterize their potential as bioresource for biofuel and fine chemicals. Bioresour Technol 226:132-144

Vizetto-Duarte C, Pereira H, De Sousa CB, Rauter AP, Albericio F, Custodio L, Barreira L, Varela J (2015) Fatty acid profile of different species of algae of the Cystoseira genus: a nutraceutical perspective. Nat Prod Res 29:1264-1270

Wahbeh MI (1997) Amino acid and fatty acid profiles of four species of macroalgae from Aqaba and their suitability for use in fish diets. Aquaculture 159:101-109

Publisher's note Springer Nature remains neutral with regard to jurisdictional claims in published maps and institutional affiliations. 